DOI: $10.15593 / 2224-9982 / 2017.50 .08$

УДК $62-97$

\author{
А.А. Селиванова, Н.Л. Бачев, Р.В. Бульбович, О.О. Матюнин
}

Пермский национальный исследовательский политехнический университет, Пермь, Россия

\author{
АНАЛИЗ ПАРАМЕТРОВ НАРУЖНОГО ПРОТИВОТОЧНОГО \\ ОХЛАЖДЕНИЯ КАМЕРЫ СГОРАНИЯ \\ В СОСТАВЕ УТИЛИЗАЦИОННОЙ ЭНЕРГОУСТАНОВКИ
}

\begin{abstract}
При разработке утилизационной камеры сгорания (КС) в составе наземных газотурбинных энергоустановок очень важным является вопрос о повышении ресурса их работы. В статье предлагается противоточное наружное охлаждение КС с продольно-оребренной рубашкой охлаждения. В качестве охладителя используется окислитель (воздух), который отбирает тепло от огневой стенки, а затем в подогретом состоянии подается в зоны горения, догорания и разбавления. При оценке температурного режима конструкционного материала конструктора в первую очередь интересует максимальная температура огневой стенки. Местоположение и значение этой температуры определяются характером распределения тепловых потоков по длине КС. В предложенной методике температуры огневой стенки определяются итерационным способом из решения уравнений баланса тепла в разных сечениях огневой стенки с точностью до $1 \%$. Представлены профили коэффициентов теплообмена в КС и рубашке охлаждения, конвективного, лучистого и суммарного тепловых потоков в КС, температур продуктов сгорания, огневой стенки и охлаждающего воздуха вдоль камеры сгорания. Показаны зависимости температур огневой стенки в зоне горения, догорания и разбавления от коэффрициента оребрения охлаждающего тракта. По результатам исследований предлагается использовать в качестве конструкционных материалов недорогие хромоникелевые сплавы типа 12X18Н10Т и X21Н5Т. Исследования показали, что применение противоточного наружного охлаждения КС с продольно-оребренной рубашкой в составе наземных газотурбинных установок приводит к значительному снижению максимальной температуры огневой стенки и является эффективным средством для увеличения ресурса работы КС.

Ключевые слова: утилизационная камера сгорания, конвективный и лучистый тепловые потоки, баланс тепла, противоточная система охлаждения, оребренная рубашка охлаждения, хромоникелевые стали, температуры газа, огневой стенки и охладителя, коэффрициент оребрения.
\end{abstract}

\author{
A.A. Selivanova, N.L. Bachev, R.V. Bulbovich, O.O. Matyunin \\ Perm National Research Polytechnic University, Perm, Russian Federation
}

\title{
ANALYSIS OF THE PARAMETERS OF THE EXTERNAL COUNTERCURRENT COOLING OF THE COMBUSTION CHAMBER IN THE COMPOSITION OF THE UTILIZATION POWER PLANT
}

\footnotetext{
When developing a recycling combustion chamber as part of terrestrial gas-turbine power plants, it is very important to increase the resource of their operation. In the work, counter-current external cooling of the combustion chamber with a longitudinal-finned cooling jacket is proposed. As a coolant, oxygen (air) is used, which takes heat from the fire wall and in the warmed state in the dilution, afterburning and burning zones, increasing the area of stable combustion. When evaluating the temperature regime of the structural material, we are primarily interested in the maximum temperature of the fire wall. The location and value of this temperature is obtained by the distribution of heat flows along the length of the combustion chamber. In the proposed technique, the temperature of the fire wall in different sections is determined by an iterative method from the solution of the heat balance equations with an accuracy of $1 \%$ for the fire wall in these sections. The profiles of the heat transfer coefficients in the combustion chamber and the cooling jacket, convective, radiant and total heat fluxes in the combustion chamber, the temperatures of the combustion products, the fire wall and the cooling air along the combustion chamber are presented. The dependencies of the temperature of the fire wall in the combustion zone, afterburning and dilution on the cooling coefficient of the cooling path are shown. Based on the results of the research, it is proposed to use inexpensive chromium-nickel alloys as structural materials. Studies have shown that the use of countercurrent external cooling of the combustion chamber with a finned jacket in the structure of gas turbine plants leads to a significant decrease in the maximum temperature of the fire wall and is an effective means for increasing the life of the combustion chamber.

Keywords: recycling combustion chamber, convective and radiant heat flows, heat balance, countercurrent cooling system, finned cooling jacket, chromium-nickel steels, temperature of gas, fire wall and cooler, coefficient of finning.
} 
При создании универсальной камеры сгорания (КС) для утилизации попутного нефтяного газа (ПНГ) переменного состава и теплопроизводительности требуется организация рабочего процесса в зоне горения при соотношениях компонентов, близких к стехиометрическому [1-3], при этом температура ПС достигает значений $T_{\mathrm{r}} \sim 2100{ }^{\circ} \mathrm{C}$. Современные конструкционные материалы обеспечивают длительный ресурс работы при рабочих температурах $T_{\text {ст }} \leq 1100{ }^{\circ} \mathrm{C}$ [4]. Следовательно, высокий ресурс утилизационной КС может быть обеспечен охлаждением огневой стенки. В данной работе рассматривается организация наружного проточного охлаждения $[5,6]$ огневой стенки КС в составе наземной энергоустановки. В качестве охладителя рассматривается окислитель (воздух), который из рубашки охлаждения в подогретом состоянии поступает в зоны горения, догорания и разбавления. Параметры теплового состояния КС определяются из решения уравнения теплового баланса для огневой стенки. Приведены зависимости конвективного, лучистого и суммарного тепловых потоков, температуры продуктов сгорания (ПС) и температуры огневой стенки по длине КС. Также приведены зависимости температуры огневой стенки в зонах горения, догорания и разбавления от высоты рубашки охлаждения и коэффициента оребрения.

Принципиальная схема наружного противоточного охлаждения утилизационной КС представлена на рис. 1.

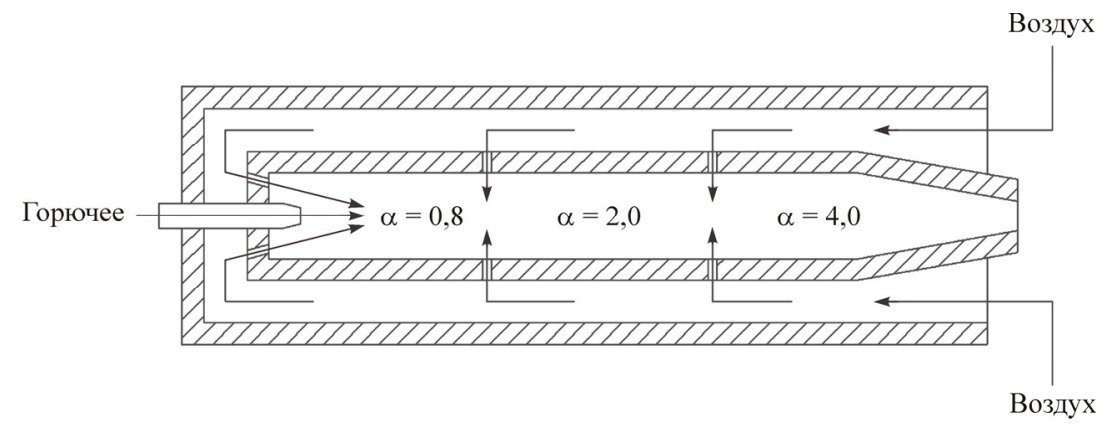

Рис. 1. Противоточная схема охлаждения утилизационной КС

Воздух от компрессора через коллектор поступает в рубашку охлаждения по противоточной схеме. В процессе движения по тракту охлаждения воздух отбирает тепло по механизму конвективного теплообмена от огневой стенки. В нагретом состоянии он сначала поступает через боковые радиальные отверстия в зону разбавления, далее в зону догорания и окончательно через струйные форсунки в зону горения. Одновременно с охлаждением огневой стенки нагретый воздух способствует расширению концентрационных пределов горения забалластированного ПНГ и устойчивости горения утилизируемого газа [7].

Локальные значения температуры огневой стенки могут быть определены из решения уравнения теплового баланса, составленного для конкретного сечения огневой стенки в установившемся режиме работы [8]:

$$
\left(q_{\mathrm{K}}\right)_{\mathrm{г}-\mathrm{cт}}+\left(q_{\text {л }}\right)_{\text {г-ст }}=\left(q_{\mathrm{K}}\right)_{\text {ст-охл }} .
$$

Уравнение (1) решается итерационным способом относительно температуры огневой стенки $T_{\text {ст }}$ до достижения требуемой точности.

Ниже приведены пояснения и последовательность определения величин, входящих в уравнение теплового баланса (1).

Конвективный тепловой поток от ПС в огневую стенку $[9,10]$

$$
\left(q_{\mathrm{K}}\right)_{\text {г-ст }}=\alpha_{\text {г-ст }}\left(T_{\text {г }}-T_{\text {ст }}\right),
$$

где $T_{\Gamma}, T_{\text {ст }}$ - температуры ПС и огневой стенки; $\alpha_{\text {г-ст }}-$ коэффициент теплообмена между ПС и огневой стенкой. 
Лучистый тепловой поток от ПС в огневую стенку [11, 12]

$$
\left(q_{\text {л }}\right)_{\text {г-ст }}=\sigma \varepsilon_{\text {ст }} \varepsilon_{\text {г }}\left(T_{\text {г }}^{4}-T_{\text {ст }}^{4}\right),
$$

где $\sigma$ - постоянная Стефана-Больцмана, $\sigma=5,67 \cdot 10^{-8} \mathrm{BT} /\left(\mathrm{M}^{2} \cdot \mathrm{K}^{4}\right) ; \varepsilon_{\text {ст }}, \varepsilon_{\text {г }}-$ степени черноты огневой стенки и ПС соответственно.

Степень черноты ПС $[12,13]$

$$
\varepsilon_{\mathrm{r}}=\varepsilon_{\mathrm{CO}_{2}}+0,9 \varepsilon_{\mathrm{H}_{2} \mathrm{O}} .
$$

Степени черноты трехатомных $\mathrm{CO}_{2}$ и $\mathrm{H}_{2} \mathrm{O}$ [12]

$$
\begin{gathered}
\varepsilon_{\mathrm{CO}_{2}}=0,71\left(10^{-5} p_{\mathrm{CO}_{2}} l\right)^{0,33}\left(\frac{T_{\mathrm{\Gamma}}}{100}\right)^{-0,5}, \\
\varepsilon_{\mathrm{H}_{2} \mathrm{O}}=0,71\left(10^{-5} p_{\mathrm{H}_{2} \mathrm{O}} l\right)^{0,6}\left(10^{-5} p_{\mathrm{\kappa}}\right)^{0,2}\left(\frac{T_{\mathrm{\Gamma}}}{100}\right)^{-1},
\end{gathered}
$$

где $p_{\mathrm{CO}_{2}}, p_{\mathrm{H}_{2} \mathrm{O}}-$ парциальные давления $\mathrm{CO}_{2}, \mathrm{H}_{2} \mathrm{O}$ в КС соответственно; $p_{\text {к }}$ - суммарное давление в КС.

Эффективная длина пути луча вычисляется как радиус полусферы, объем которой равен объему КС:

$$
l=\left(\frac{3 V}{2 \pi}\right)^{\frac{1}{3}}
$$

где $V$ - объем КС.

Суммарный тепловой поток от ПС в огневую стенку

$$
\left(q_{\Sigma}\right)_{\text {г-ст }}=\left(q_{\mathrm{K}}\right)_{\mathrm{\Gamma}-\mathrm{cT}}+\left(q_{\mathrm{J}}\right)_{\mathrm{r}-\mathrm{cT}} .
$$

Конвективный тепловой поток от огневой стенки в охладитель

$$
\left(q_{\mathrm{K}}\right)_{\text {ст-охл }}=\alpha_{\text {ст-охл }} \varphi\left(T_{\text {ст-охл }}-T_{\text {охл }}\right),
$$

где $\alpha_{\text {ст-охл }}$ - коэффициент теплообмена между огневой стенкой и охладителем; $\varphi$ - коэффициент оребрения охлаждающего тракта; $T_{\text {охл }}$ - температура охладителя.

Температура стенки со стороны охладителя

$$
T_{\text {ст-охл }}=T_{\text {ст }}-\frac{\left(q_{\Sigma}\right)_{\text {г-ст }} \delta_{\text {ст }}}{\lambda_{\text {ст }}},
$$

где $\delta_{\text {ст }}, \lambda_{\text {ст }}$ - толщина и коэффициент теплопроводности огневой стенки.

Коэффициент теплообмена между ПС и огневой стенкой вычисляется по критериальному уравнению [9]

$$
\frac{\alpha_{\mathrm{r}-\mathrm{Cr}} d_{\mathrm{K}}}{\lambda_{г}}=0,023\left(\frac{4 G_{\mathrm{r}}}{\pi d_{\mathrm{K}} \mu_{\mathrm{r}}}\right)^{0,8}\left(\frac{\mu_{\mathrm{r}} C_{p \Gamma}}{\lambda_{\mathrm{r}}}\right)^{0,4},
$$

где $d_{\text {к }}$ - диаметр КС; $G_{\text {г }}$ - расход ПС; $\mu_{г}, \lambda_{г}, C_{p г}$ - коэффициенты динамической вязкости, теплопроводности и изобарная теплоемкость ПС соответственно.

Коэффициент теплообмена между огневой стенкой и охлаждающим воздухом вычисляется по критериальному уравнению [9]

$$
\frac{\alpha_{\text {гсст }} d_{\text {охл }}}{\lambda_{\text {охл }}}=0,023\left(\frac{\rho_{\text {охл }} W_{\text {охл }}}{\mu_{\text {охл }}}\right)^{0,8}\left(\frac{\mu_{\text {охл }} C_{\text {рохл }}}{\mu_{\text {охл }}}\right)^{0,4},
$$


где $\mu_{\text {охл }}, \mu_{\text {охл }}, C_{\text {рохл }}, \rho_{\text {охл }}-$ коэффициенты динамической вязкости, теплопроводности, изобарная теплоемкость и плотность охлаждающего воздуха соответственно.

Скорость охлаждающего воздуха

$$
W_{\text {охл }}=\frac{G_{\text {охл }}}{\rho_{\text {охл }} \chi F_{\text {охл }}},
$$

где $G_{\text {охл }}$ - расход охлаждающего воздуха; $\chi$ - коэффициент живого сечения оребренного кольцевого канала; $F_{\text {охл }}-$ поперечное сечение неоребренного кольцевого канала.

Подогрев охлаждающего воздуха в кольцевой рубашке охлаждения на участке длиной $d l$ находится из решения уравнения теплового баланса $[14,15]$

$$
\left(q_{\Sigma}\right)_{\text {гсст }} \pi d_{\mathrm{K}} d l=G_{\text {охл }} C_{\text {рохл }}\left[T_{\text {охл }}-\left(T_{\text {охл }}\right)_{\mathrm{Bx}}\right] \text {, }
$$

$\left(T_{\text {охл }}\right)_{\text {вх }}$ - температура охлаждающего воздуха на входе в участок длинной $d l$.

Для интенсификации процесса теплообмена предлагается применение оребренной рубашки охлаждения с продольными ребрами.

Схема продольно-оребренной рубашки охлаждения представлена на рис. 2.

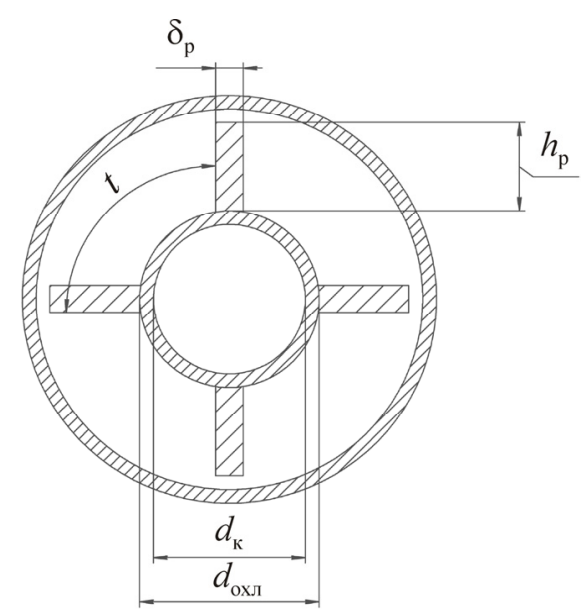

Рис. 2. Схема продольно-оребренной рубашки охлаждения

Площадь продольно-оребренной поверхности теплообмена

$$
F_{\mathrm{p}}=\left(\pi d_{\text {охл }}+2 n_{\mathrm{p}} h_{\mathrm{p}}\right) L_{\Sigma},
$$

где $n_{\mathrm{p}}, h_{\mathrm{p}}$ - количество и высота ребер соответственно; $L_{\Sigma}-$ длина КС.

Площадь внутренней гладкой поверхности рубашки охлаждения

$$
F_{\text {гл }}=\pi d_{\text {охл }} L_{\Sigma} \cdot
$$

Таким образом, коэффициент оребрения

$$
\varphi=\frac{F_{\mathrm{p}}}{F_{\text {гл }}}=1+\frac{2 n_{\mathrm{p}} h_{\mathrm{p}}}{\pi d_{\text {охл }} .}
$$

Коэффициент живого сечения рубашки охлаждения

$$
\chi=1-\frac{4 n_{\mathrm{p}} \delta_{\mathrm{p}} h_{\mathrm{p}}}{\pi d_{\text {охл }}^{2}},
$$

где $\delta_{\mathrm{p}}$ - толщина ребра. 
Возможные коэффициенты оребрения рассматриваемого охлаждающего тракта приведены в табл. 1.

Таблица 1

Коэффициенты оребрения охлаждающего тракта

\begin{tabular}{|c|c|c|c|c|c|}
\hline \multirow{2}{*}{$n_{\mathrm{p}}$} & \multirow{2}{*}{$t$, мм } & \multicolumn{4}{|c|}{ Коэффициенты оребрения } \\
\cline { 3 - 6 } & & $h_{\mathrm{p}}=3 \mathrm{мм}$ & $h_{\mathrm{p}}=5 \mathrm{мм}$ & $h_{\mathrm{p}}=10 \mathrm{мм}$ & $h_{\mathrm{p}}=15 \mathrm{Mм}$ \\
\hline 0 & 0 & 1 & 1 & 1 & 1 \\
\hline 4 & 85 & 1,071 & 1,118 & 1,236 & 1,353 \\
\hline 6 & 57 & 1,106 & 1,177 & 1,353 & 1,53 \\
\hline 8 & 42 & 1,141 & 1,236 & 1,471 & 1,707 \\
\hline 12 & 28 & 1,212 & 1,353 & 1,707 & 2,06 \\
\hline 20 & 17 & 1,353 & 1,589 & 2,178 & 2,766 \\
\hline 28 & 12 & 1,495 & 1,824 & 2,649 & 3,473 \\
\hline 34 & 10 & 1,601 & 2,001 & 3,002 & 4,003 \\
\hline 42 & 8 & 1,742 & 2,236 & 3,473 & 4,709 \\
\hline
\end{tabular}

По разработанному алгоритму проведены расчетные исследования противоточного наружного охлаждения с различной степенью оребренности охлаждающего тракта. Расчеты проведены применительно к КС тепловой мощностью 200 кВт, геометрические, режимные и тепловые параметры которой представлены в табл. 2.

Таблица 2

Геометрические, режимные и тепловые параметры КС

\begin{tabular}{|l|c|c|c|}
\hline \multicolumn{1}{|c|}{ Название } & Обозначение & Размерность & Величина \\
\hline Коэффициент избытка воздуха в зоне горения & $\alpha_{1}$ & - & 0,8 \\
\hline Коэффициент избытка воздуха в зоне догорания & $\alpha_{2}$ & - & 2,0 \\
\hline Коэффициент избытка воздуха в зоне разбавления & $\alpha_{3}$ & - & 4,0 \\
\hline Длина зоны горения & $L_{1}$ & $\mathrm{M}$ & 0,063 \\
\hline Длина зоны догорания & $L_{2}$ & $\mathrm{M}$ & 0,078 \\
\hline Длина зоны разбавления & $L_{3}$ & $\mathrm{M}$ & 0,036 \\
\hline Длина КС & $L_{\Sigma}$ & $\mathrm{M}$ & 0,176 \\
\hline Внутренний диаметр КС & $d_{\text {к }}$ & $\mathrm{M}$ & 0,1 \\
\hline Расход воздуха в зоне горения & $G_{\text {ок1 }}$ & кг/с & 0,054 \\
\hline Расход воздуха в зоне догорания & $G_{\text {ок2 }}$ & кг/с & 0,081 \\
\hline Расход воздуха в зоне разбавления & $G_{\text {окз }}$ & кг/с & 0,135 \\
\hline Расход воздуха на входе в рубашку охлаждения & $G_{\text {ок }}$ & кг/с & 0,269 \\
\hline Толщина огневой стенки & $\delta_{\text {ст }}$ & м & 0,004 \\
\hline Толщина ребра & $\delta_{\text {р }}$ & м & 0,004 \\
\hline Коэффициент теплопроводности материала огневой стенки & $\lambda_{\text {ст }}$ & Вт/(м·К) & 25 \\
\hline Температура воздуха на входе в рубашку охлаждения & $T_{\text {вх }}$ & К & 412 \\
\hline Степень черноты огневой стенки & $\varepsilon_{\text {ст }}$ & - & 0,8 \\
\hline Внутренний диаметр рубашки охлаждения & $d_{\text {охл }}$ & м & 0,108 \\
\hline
\end{tabular}

На рис. 3 показано распределение коэффициентов теплообмена между ПС и огневой стенкой и между огневой стенкой и охлаждающим воздухом по длине КС. 


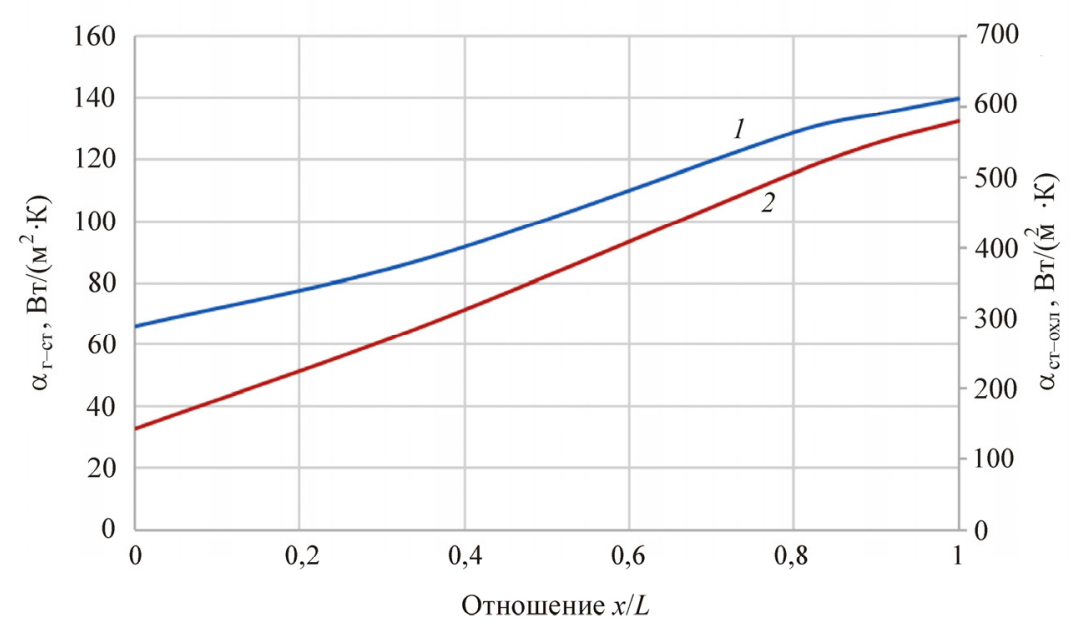

Рис. 3. Распределение коэффициентов теплообмена в КС и рубашке охлаждения по длине камеры: 1 - коэффициент теплообмена между ПС и огневой стенкой; 2 - коэффициент теплообмена между огневой стенкой и охладителем

Коэффициенты теплообмена в КС и рубашке охлаждения увеличиваются по длине камеры, что связано с увеличением скорости ПС по длине камеры и скорости охлаждающего воздуха по длине рубашки охлаждения из-за переменных расходов вторичного воздуха, который одновременно является и окислителем, и охлаждающим агентом.

На рис. 4 показано распределение тепловых потоков от ПС в огневую стенку по длине КС.

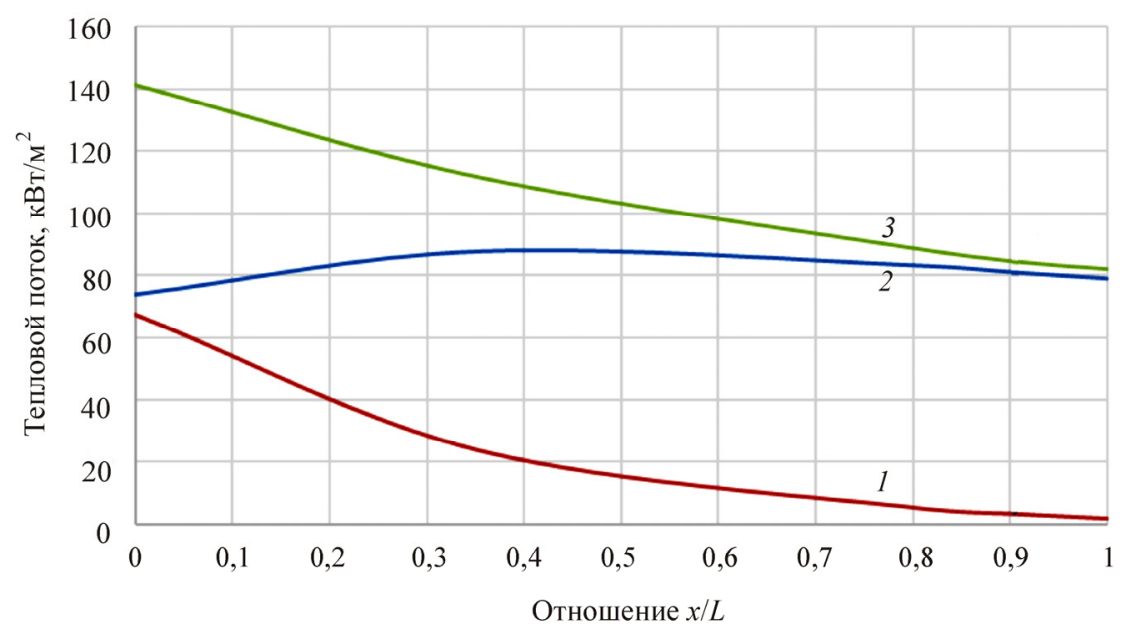

Рис. 4. Распределение тепловых потоков: 1 - лучистый тепловой поток;

2 - конвективный тепловой поток; 3 - суммарный тепловой поток

Уменьшение лучистого теплового потока по длине камеры связано со значительным уменьшением температуры ПС в зонах догорания и разбавления по сравнению с зоной горения. Конвективный тепловой поток по длине камеры сохраняется практически постоянным $\sim 80$ кВт/м². Это обстоятельство связано с увеличением коэффициента теплообмена между ПС и огневой стенкой при одновременном уменьшении температуры ПС по длине камере. Суммарный тепловой поток по длине камеры уменьшается примерно на $40 \%$.

На рис. 5 показано распределение температур газа, огневой стенки и охлаждающего воздуха по длине КС. 


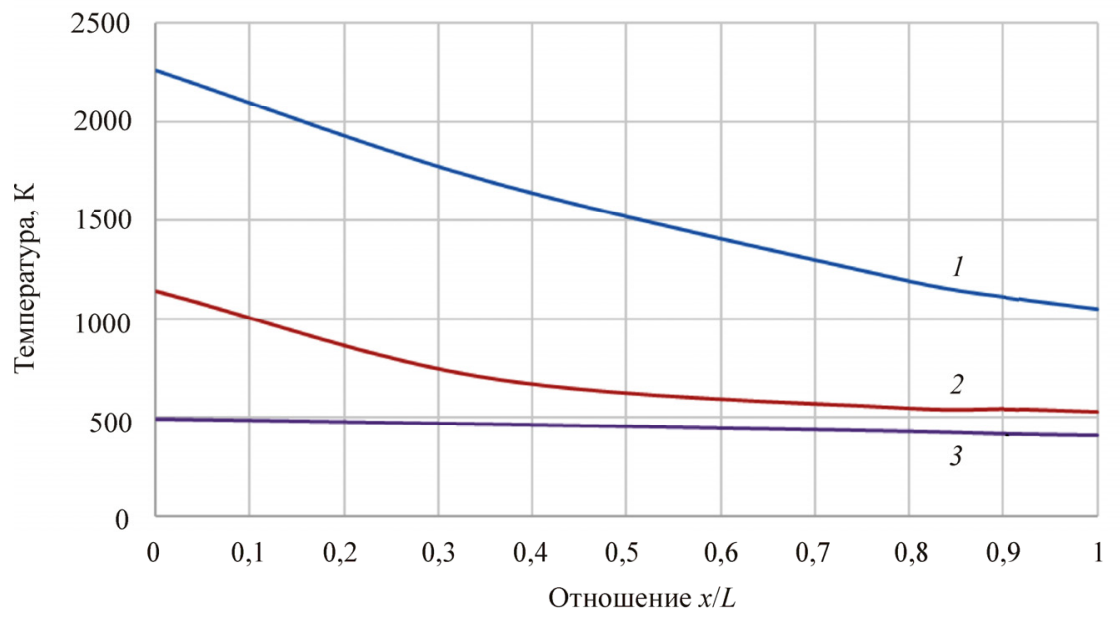

Рис. 5. Распределение температур по длине КС: 1 - температура газа; 2 - температура огневой стенки; 3 - температура охладителя

Уменьшение температуры газа по длине КС объясняется увеличением коэффициента избытка воздуха в зонах догорания и разбавления по сравнению с зоной горения. Температура огневой стенки имеет максимальное значение в зоне горения. Именно по максимальной температуре стенки следует выбирать марку конструкционного материала. Для изготовления огневой стенки можно рекомендовать сравнительно недорогие материалы 12X18Н10T и Х21Н5Т [4]. Температура охлаждающего воздуха вдоль рубашки охлаждения увеличивается в сторону зоны горения на $14 \%$.

Важнейшими параметрами, влияющими на температуру огневой стенки, являются коэффициент оребрения и высота рубашки охлаждения. На рис. 6 и 7 представлены зависимости температуры огневой стенки в зонах горения, догорания и разбавления от коэффициента оребрения при высоте охлаждающего тракта $h_{\text {охл }}=0,005$ м $h_{\text {охл }}=0,015$ м соответственно.

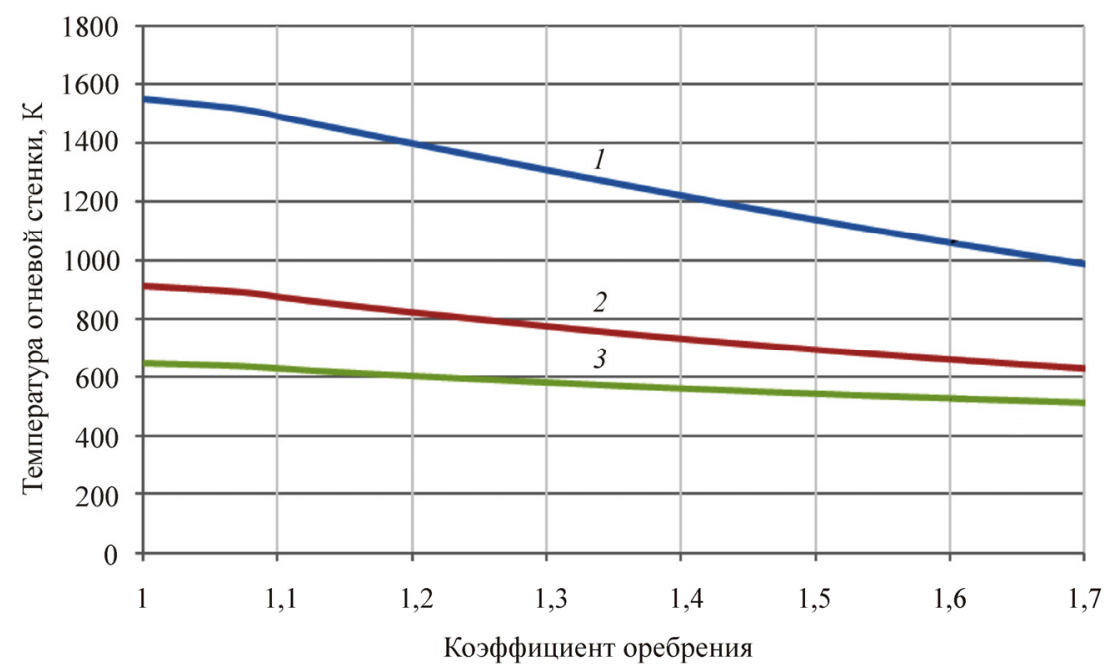

Рис. 6. Зависимость температур огневой стенки от коэффициента оребрения:

1 - температура стенки в зоне горения; 2 - температура стенки в зоне догорания; 3 - температура стенки в зоне разбавления; $h_{\text {охл }}=0,005 \mathrm{м}$ 


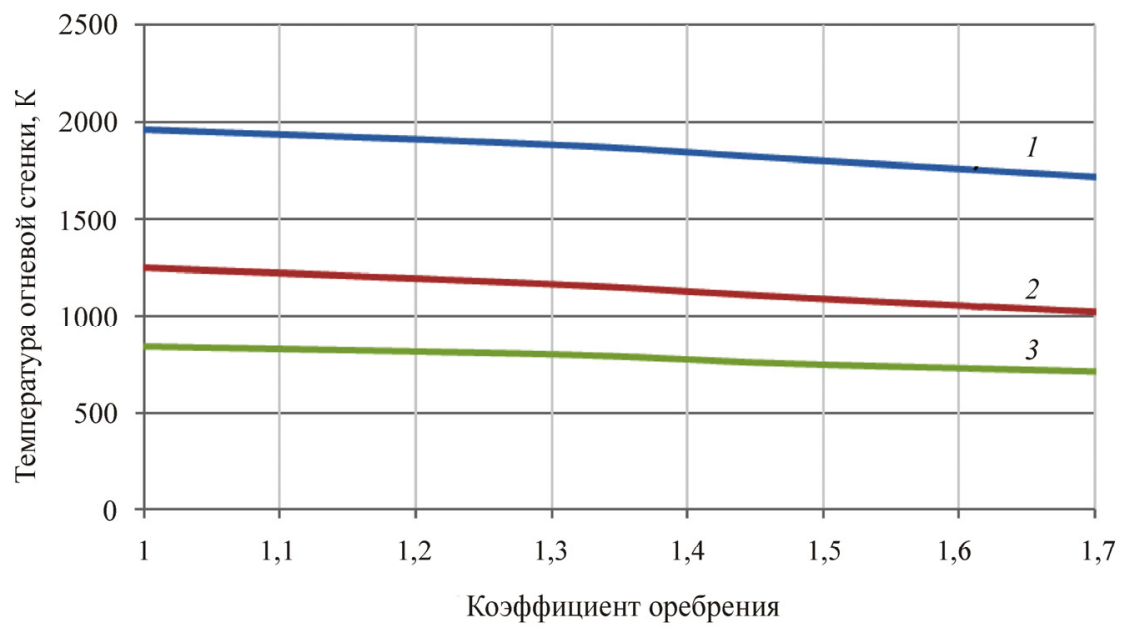

Рис. 7. Зависимость температур огневой стенки от коэффициента оребрения:

1 - температура стенки в зоне горения; 2 - температура стенки в зоне догорания; 3 - температура стенки в зоне разбавления; $h_{\text {охл }}=0,015 \mathrm{M}$

Анализ данных на рис. 6 и 7 показывает, что увеличение коэффициента оребрения в 1,7 раза приводит к понижению максимальной температуры огневой стенки до $64 \%$. Уменьшение высоты рубашки охлаждения в 3 раза снижает максимальную температуру огневой стенки до $20 \%$. Следовательно, оребрение охлаждающего тракта является очень сильным фактором для увеличения ресурса работы КС. Изменение коэффициента оребрения возможно за счет изменения шага оребрения (количества ребер) и высоты ребра.

Таким образом, исследования показали, что применение противоточного наружного охлаждения утилизационной КС с оребренной поверхностью теплообмена в составе наземных газотурбинных установок приводит к значительному снижению максимальной температуры огневой стенки и является эффективным средством для увеличения ресурса работы КС.

\section{Библиографической список}

1. Выбор геометрических, режимных и тепловых параметров высокоресурсной камеры сгорания для утилизации ПНГ / О.А. Бетинская (О.А. Зуева), Н.Л. Бачев, Р.В. Бульбович, А.М. Клещевников // Газовая промышленность. - 2013. - № 698. - С. 94-97.

2. Выбор геометрических, режимных и тепловых параметров высокоресурсной камеры сгорания для утилизации попутного нефтяного газа / О.А. Бетинская (О.А. Зуева), Н.Л. Бачев, Р.В. Бульбович, А.М. Клещевников // Вестник Пермского национального исследовательского политехнического университета. Аэрокосмическая техника. - 2013. - № 34. - С. 40-51.

3. Выбор режимных и геометрических параметров камеры сгорания для утилизации попутного нефтяного газа / О.А. Бетинская (О.А. Зуева), Н.Л. Бачев, Р.В. Бульбович, А.М. Клещевников // Аэрокосмическая техника, высокие технологии и инновации: тез. докл. XIV Всерос. науч.-техн. конф. (Пермь, 20-21 ноября 2013 г.). - Пермь: Изд-во Перм. нац. исслед. политехн. ун-та, 2014. - С. 56-58.

4. Гольдштейн М.И., Грачев С.В., Векслер Ю.Г. Специальные стали. - М.: Металлургия, 1985. $408 \mathrm{c}$.

5. Теория ракетных двигателей / В.Е. Алемасов [и др.]. - М.: Машиностроение, 1980. - 533 с.

6. Добровольский М.В. Жидкостные ракетные двигатели. - М.: Изд-во МГТУ им. Н.Э. Баумана, 2005. $-488 \mathrm{c}$.

7. Бетинская О.А. (Зуева О.А.). Концентрационные пределы горения попутных нефтяных газов // Вестник Пермского национального исследовательского политехнического университета. Аэрокосмическая техника. - 2014. - № 37. - С. 140-153.

8. Теплообмен в камере сгорания для утилизации попутного нефтяного газа / О.А. Бетинская (О.А. Зуева), Н.Л. Бачев, Р.В. Бульбович, А.М. Клещевников // Вестник Пермского национального исследовательского политехнического университета. Аэрокосмическая техника. - 2013. - № 34. - С. 52-63. 
9. Кошкин В.К. Основы теплопередач в авиационной и ракетно-космической технике. - М.: Машиностроение, 1975. - 624 с.

10. Кутателадзе С.С. Основы теории теплообмена. - Новосибирск: Наука, 1970. - 659 с.

11. Сударев А.В., Антоновский В.И. Камеры сгорания газотурбинных установок. Теплообмен. Л.: Машиностроение, 1985. - 272 с.

12. Андрианов В.Н. Основы радиационного и сложного теплообмена. - М.: Энергия, 1972. - 464 с.

13. Антоновский В.И., Акулов В.А., Шведков В.Н. Результаты стендовых испытаний камеры сгорания ГТЭ-150 при среднемассовой температуре продуктов сгорания $1100{ }^{\circ} \mathrm{C} / /$ Тр. Науч.-производств. объединения по исследованию и проектированию энергетического оборудования им. И.И. Ползунова (НПО ЦКТИ). - 1990. - Вып. 261. - С. 151-156.

14. Дрегалин А.Ф., Черенков А.С. Общие методы теории высокотемпературных процессов в тепловых двигателях. - М.: Янус-К, 1997. - 328 с.

15. Пчелкин Ю.М. Камеры сгорания газотурбинных двигателей. - М.: Машиностроение, 1985. - 280 с.

\section{References}

1. Betinskaya O.A. (Zuyeva O.A.), Bachev N.L., Bul'bovich R.V., Kleshchevnikov A.M. Vybor geometricheskikh, rezhimnykh i teplovykh parametrov vysokoresursnoy kamery sgoraniya dlya utilizatsii PNG [The choice of geometric, regime and thermal parameters of a high-resource combustion chamber for utilization of associated petroleum gas]. Gazovaya promyshlennost, 2013, no. 698, pp. 94-97.

2. Betinskaya O.A. (Zuyeva O.A.), Bachev N.L., Bul'bovich R.V., Kleshchevnikov A.M. Vybor geometricheskikh, rezhimnykh i teplovykh parametrov vysokoresursnoy kamery sgoraniya dlya utilizatsii poputnogo neftyanogo gaza [The choice of geometric, regime and thermal parameters of a high-resource combustion chamber for utilization of associated petroleum gas]. Vestnik PNIPU. Aerokosmicheskaya tekhnika, 2013, no. 34, pp. 40-51.

3. Betinskaya O.A. (Zuyeva O.A.), Bachev N.L., Bul'bovich R.V., Kleshchevnikov A.M. Vybor rezhimnykh i geometricheskikh parametrov kamery sgoraniya dlya utilizatsii poputnogo neftyanogo gaza [Selection of regime and geometric parameters of the combustion chamber for utilization of associated petroleum gas]. Aerokosmicheskaya tekhnika, vysokiye tekhnologii i innovatsii: tezisy dokladov XIV Vserossiyskoy nauchno-tekhnicheskoy konferentsii. Perm: Izdatel'stvo PNIPU, 2014, pp. 56-58.

4. Gol'dshteyn M.I., Grachev S.V., Veksler YU.G. Spetsial'nyye stali [Special steels]. Moscow: Metallurgiya, 1985, 408 p.

5. Alemasov V.Ye. i dr. Teoriya raketnykh dvigateley [Theory of rocket engines]. Moscow: Mashinostroyeniye, 1980, $533 \mathrm{p}$.

6. Dobrovol'skiy M.V. Zhidkostnyye raketnyye dvigateli [Liquid rocket engines]. Moscow: Izd-vo MGTU im. N.E. Baumana, 2005, 488 p.

7. Betinskaya O.A. (O.A. Zuyeva). Kontsentratsionnyye predely goreniya poputnykh neftyanykh gazov [Concentration limits of combustion of associated petroleum gases]. Vestnik PNIPU. Aerokosmicheskaya tekhnika, 2014, no. 37, pp. 140-153.

8. Betinskaya O.A. (Zuyeva O.A.), Bachev N.L., Bul'bovich R.V., Kleshchevnikov A.M. Teploobmen v kamere sgoraniya dlya utilizatsii poputnogo neftyanogo [Heat exchange in the combustion chamber for the utilization of associated petroleum gas]. Vestnik PNIPU. Aerokosmicheskaya tekhnika, 2013, no. 34, pp. 52-63.

9. Koshkin V.K. Osnovy teploperedach v aviatsionnoy i raketno-kosmicheskoy tekhnike [Fundamentals of heat transfer in aviation and rocket and space technology]. Moscow: Mashinostroyeniye, 1975, 624 p.

10. Kutateladze S.S. Osnovy teorii teploobmena [Fundamentals of the theory of heat transfer]. Novosibirsk: Nauka, 1970, 659 p.

11. Sudarev A.V., Antonovskiy V.I. Kamery sgoraniya gazoturbinnykh ustanovok. Teploobmen. [Combustion chambers of gas turbine installations. Heat exchange]. Leningrad: Mashinostroyeniye, 1985, 272 p.

12. Andrianov V.N. Osnovy radiatsionnogo i slozhnogo teploobmena [Fundamentals of radiation and complex heat transfer]. Moscow: Energiya, 1972, 464 p.

13. Antonovskiy V.I., Akulov V.A., Shvedkov V.N. Rezul'taty stendovykh ispytaniy kamery sgoraniya GTE-150 pri srednemassovoy temperature produktov sgoraniya $1100{ }^{\circ} \mathrm{C}$ [Results of bench tests of the combustion chamber GTE-150 at the average mass temperature of the combustion products $\left.1100{ }^{\circ} \mathrm{C}\right]$. Trudy Nauchnoproizvodstvennogo ob"yedineniya po issledovaniyu $i$ proyektirovaniyu energeticheskogo oborudovaniya im. I.I. Polzunova. 1990, no. 261, pp. 151-156. 
14. Dregalin A.F., Cherenkov A.S. Obshchiye metody teorii vysokotemperaturnykh protsessov v teplovykh dvigatelyakh [General methods of the theory of high-temperature processes in thermal engines]. Moscow: Yanus-K, 1997, 328 p.

15. Pchelkin YU.M. Kamery sgoraniya gazoturbinnykh dvigateley [Combustion chambers of gas turbine engines]. Moscow: Mashinostroyeniye, 1985, 280 p.

\title{
Об авторах
}

Селиванова Алена Алексеевна (Пермь, Россия) - студентка ФГБОУ ВО ПНИПУ (614990, г. Пермь, Комсомольский пр., д. 29, e-mail: alyona1203@gmail.com).

Бачев Николай Леонидович (Пермь, Россия) - кандидат технических наук, профессор кафедры «Ракетно-космическая техника и энергетические системы» ФГБОУ ВО ПНИПУ (614990, г. Пермь, Комсомольский пр., д. 29, e-mail: bn154@yandex.ru).

Бульбович Роман Васильевич (Пермь, Россия) - доктор технических наук, профессор кафедры «Ракетно-космическая техника и энергетические системы» ФГБОУ ВО ПНИПУ (614990, г. Пермь, Комсомольский пр., д. 29, e-mail: dekan_akf@pstu.ru).

Матюнин Олег Олегович (Пермь, Россия) - старший преподаватель кафедры «Ракетнокосмическая техника и энергетические системы» ФГБОУ ВО ПНИПУ (614990, г. Пермь, Комсомольский пр., д. 29, e-mail: matoleg@gmail.com).

\begin{abstract}
About the authors
Alyona A. Selivanova (Perm, Russian Federation) - Student, Perm National Research Polytechnic University (29, Komsomolsky av., Perm, 614990, Russian Federation, e-mail: alyona1203@gmail.com).

Nikolay L. Bachev (Perm, Russian Federation) - Ph. D. in Technical Sciences, Professor, Rocket and Space Engineering and Power Generating Systems Department, Perm National Research Polytechnic University (29, Komsomolsky av., Perm, 614990, Russian Federation, e-mail: bnl54@yandex.ru).

Roman V. Bulbovich (Perm, Russian Federation) - Doctor of Technical Sciences, Professor, Rocket and Space Engineering and Power Generating Systems Department, Perm National Research Polytechnic University (29, Komsomolsky av., Perm, 614990, Russian Federation, e-mail: dekan_akf@ pstu.ru).

Oleg O. Matyunin (Perm, Russian Federation) - Senior Lecturer, Rocket and Space Engineering and Power Generating Systems Department, Perm National Research Polytechnic University (29, Komsomolsky av., Perm, 614990, Russian Federation, e-mail: matoleg@gmail.com).
\end{abstract}

Получено 20.07.2017 